\title{
Effect of Ultra-high Pressure Treatment on the Chemical Properties, Colour and Sensory Quality of Young Red Wine
}

\author{
X. Sun ${ }^{\#}$ X. Chen", L. Li, T. Ma, F. Zhao, W. Huang, J. Zhan* \\ College of Food Science and Nutritional Engineering, Beijing Key Laboratory of Viticulture and Oenology, China Agricultural \\ University, Beijing 100083, China \\ \#These authors contributed equally to this work
}

Submitted for publication: June 2015

Accepted for publication: August 2015

Key words: UHP, chemical properties, sensory quality, colour

\begin{abstract}
The effects of ultra-high pressure (UHP) treatment on the chemical properties, colour and sensory quality of young red wine were studied. UHP did not significantly affect the alcohol content, and the methanol content was higher than that of the control, with the latter first increasing and then decreasing with the increase in the pressure or period of treatment. The glycerol content was also markedly changed by UHP, although without a regular pattern. The $\mathrm{pH}$ value was not markedly changed by the treatments, and the contents of total acids and volatile acids were scarcely affected. The fructose and glucose contents were clearly changed according to the different treatment conditions. The tartaric acid, citric acid and lactic acid levels showed evident changes, whereas the malic acid level was not changed by UHP treatment. The trend of these changes was similar to what occurs during natural ageing. As the pressure of the treatment was increased to $200 \mathrm{MPa}$, the chroma value increased, followed by a decline upon higher pressure treatments. The hue of the wine was significantly changed by treatment at different pressures, reaching the highest value after treatment at $400 \mathrm{MPa}$ and then decreasing with increasing pressure. The chroma and hue values of the wine were changed significantly according to the duration of the UHP. After UHP, the appearance, aroma and taste of the wine was improved, with the score for appearance obviously increased. When the wine was treated at 500 MPa for $30 \mathrm{~min}$, its sensory quality received the highest score.
\end{abstract}

\section{INTRODUCTION}

Ultra-high pressure (UHP) processing, also called highhydrostatic pressure (HHP) processing, is a method by which food is sealed in containers or placed in water or other liquids under pressure to sterilise it and inactivate enzymes, or to change the functional properties of a product (Chen et al., 2012; Zhao et al., 2014). Because this treatment has several advantages over the traditional methods for food conservation and hygiene, UHP treatment is of great value to the food-processing industry and has been widely applied to a range of different foods over the last several decades.

Wine is the second most popular alcoholic drink in the world (Ma et al., 2014; Sun et al., 2014). The UHP processing of wines has been studied, including its use in sterilisation as a substitute for the addition of sulphur dioxide and in accelerating ageing, among others (Sencer, 2012). Wine is traditionally aged in oak barrels, which is a lengthy, very expensive and risky process (Chen et al., 2012). Using advanced technologies such as UHP treatment, high-voltage pulsed electric field treatment, electromagnetic field treatment and microwave treatment to simulate this process would save much time and expense. Due to these advantages, a whole range of food products treated using the advanced methods, such as fruit juices, seafood and meat products, can be found on market shelves throughout the world, but no UHP-treated wine has been introduced into the market (Matser et al., 2004; Park et al., 2007; 2009; Sencer, 2012), mainly because the correlation studies are still not sufficiently mature.

Many researchers have reported on the effects of the UHP treatment of wines, focusing mostly on certain aspects. Firstly, the effect of UHP treatment on the chemical composition of functional components, including phenolic acids, flavan-3-ols, proanthocyanidins (Chen et al., 2012), anthocyanins (Morata et al., 2012; Del Pozo-Insfran et al., 2007) and volatile compounds (Morata et al., 2012), have been studied. After UHP treatment, the concentration of phenolic acids was increased, whereas the levels of flavan-3-ols were decreased. The content and structure of proanthocyanidins was also changed by this treatment, with a trend that was

*Corresponding author: E-mail address: zhanjicheng@cau.edu.cn [Tel./Fax: +86-10-62737553]

Acknowledgements: We express our gratitude for funding from the Fundamental Research Funds for the Central Universities in China (2015SP004), the National Natural Science Foundation Project (31471835) and the Special Fund for Agro-scientific Research in the Public Interest (2012BAD31B05) 
similar to that occurring during natural ageing (Del PozoInsfran et al., 2007; Chen et al., 2012; Morata et al., 2012). Furthermore, UHP treatment avoided the reduction of the volatile compound contents that occurs when using traditional techniques for microbiologically stabilising wines (Morata et al., 2012). Secondly, the effect of UHP treatment on the stability of wines has been studied (Corrales et al., 2008; Tabilo-Munizaga et al., 2014). It was found that UHP treatment may contribute to protein stabilisation (TabiloMunizaga et al., 2014) and cause anthocyanin condensation (Corrales et al., 2008) in wines. Thirdly, the effect of UHP treatment on pasteurisation or its use as a substitute for the addition of sulphur dioxide was studied, and the feasibility of UHP treatment for wine pasteurisation was demonstrated (Delfini \& Conterno, 1995; Mok et al., 2006; Morata et al., 2012; Santos et al., 2013a; 2013b; Morata et al., 2015).

In addition to the aspects mentioned above, the basic physical and chemical indices, sensory properties and colour are the foundation of wine quality (Li et al., 2006). Whether UHP treatment affects these indices is also very important to the application of UHP technology by the wine industry. However, to the best of our knowledge, few studies have focused on the effect of UHP treatment on these indices.

Therefore, the aim of the present investigation was to analyse the effects of different UHP treatments on the basic physical and chemical indices, sensory properties and colour of wine. These results are expected to facilitate the successful use of UHP technology by the wine industry as soon as possible.

\section{MATERIALS AND METHODS}

\section{Preparation of wine samples}

The wine samples were obtained from Xinjiang, China, from the 2009 vintage, and the variety was Cabernet Sauvignon. Fresh wine was sampled directly from the fermentation tank, filtered and then stored at $15^{\circ} \mathrm{C}$ in bottles in the dark until the experiments were conducted. All of the experiments were completed within two weeks. The first group of wine was treated at $100 \mathrm{MPa}, 200 \mathrm{MPa}, 300 \mathrm{MPa}, 400 \mathrm{MPa}, 500 \mathrm{MPa}$ and $600 \mathrm{MPa}$ for $30 \mathrm{~min}$. The second group of wine was treated for $5 \mathrm{~min}, 10 \mathrm{~min}, 20 \mathrm{~min}, 30 \mathrm{~min}, 45 \mathrm{~min}$ and $60 \mathrm{~min}$ at $500 \mathrm{MPa}$. Untreated wine was used as the control group. The wine was placed in $100 \mathrm{~mL}$ polyethylene terephthalate bottles for UHP processing. The UHP treatments were conducted using a hydrostatic pressurisation unit (HPP650, Baotou Kefa Co. Ltd., Baotou, Inner Mongolia, China) with a capacity of $7.0 \mathrm{~L}$ at ambient temperature (approximately $25^{\circ} \mathrm{C}$ ). This unit pressurised at $2 \mathrm{MPa} / \mathrm{s}$, and the decompression time was less than $3 \mathrm{~s}$. Distilled water was used as the pressure-transmitting fluid. The pressureholding treatment period in this study did not include the pressurisation and decompression periods. Under adiabatic compression, the temperature of the water increases approximately $3^{\circ} \mathrm{C}$ for every $100 \mathrm{MPa}$ pressure increase at room temperature (Pehl et al., 2000; Balasubramaniam et al., 2008). When pressurisation was accomplished, the sample temperature quickly dropped to its initial temperature due to the heat transfer from the samples to the stainless steel wall of the vessel (Chen \& Hoover, 2003). Therefore, when the initial temperature of the treated wine was approximately $25^{\circ} \mathrm{C}$, due to the non-adiabatic conditions and the compressedheat transfer, the highest sample temperature reached (when the pressure was $600 \mathrm{MPa}$ ) was far less than $40^{\circ} \mathrm{C}$ during the UHP treatments in this study. The contribution of the estimated highest sample temperature reached during UHP treatment to the tested indices was considered negligible (Zhao et al., 2014). All of the treated samples were filtered through a $0.45 \mu \mathrm{m}$ organic Millipore filter prior to analysis (Merck Millipore, Billerica, MA, USA).

\section{Determination of the physical and chemical properties}

Fourier transform infrared spectroscopy (FTIR) was conducted using a wine analyser (F17-WineScan FT120, Foss Co., Ltd., Hillerød, Denmark) to determine the physical and chemical properties of the samples. This instrument could rapidly analyse many indices of the wine samples, including the contents of alcohol, methanol and glycerol, the $\mathrm{pH}$ value and the contents of total acids, volatile acids, fructose, glucose, tartaric acid, citric acid, lactic acid and malic acid, among others (Soriano et al., 2007). Before analysis, standards were used to calibrate the instrument. The wine samples were analysed directly without any further treatment.

\section{Determination of the chroma and hue values}

After the $\mathrm{pH}$ of the samples was adjusted to 3.6, the samples were filtered through a $0.45 \mu \mathrm{m}$ membrane, and then, using deionised water as the blank control, the absorbance values at wavelengths of $420 \mathrm{~nm}, 520 \mathrm{~nm}$ and $620 \mathrm{~nm}$ were measured in triplicate using a UV-1601 ultraviolet spectrophotometer (Shimadzu Co. Ltd., Kyoto, Japan). The chroma value was the sum of the absorbance values at $620 \mathrm{~nm}, 520 \mathrm{~nm}$ and $420 \mathrm{~nm}$, and the hue value was the ratio of the absorbance values at $420 \mathrm{~nm}$ and $520 \mathrm{~nm}$ (Wyszecki \& Stiles, 1982; CIE, 2004).

\section{Evaluation of the sensory quality}

The samples treated using UHP were evaluated in triplicate by six professionals skilled in blind tasting (GB/T 15038 , 2006; Han \& Tong, 2009). The panellists were trained at the Beijing Key Laboratory of Viticulture and Oenology of the China Agricultural University, and included two males and five females of ages ranging from 20 to 50 years, all of whom were experienced tasters and had previously participated in similar studies. The sensory evaluation was performed using the descriptive analysis method (Winiarski et al., 1996; GB/T 15038-2006; Han \& Tong, 2009). Judging was performed in a professional-standard room that met the ISO Norm 8589 (1988). The taste evaluation table was slightly modified from that of Winiarski et al. (1996) and is shown in Table 1.

\section{Statistical analysis}

The experimental results were presented as the mean values \pm SE of three parallel measurements. The statistical analyses were performed using the SigmaPlot 11.0 program and SPSS 17.0 software. 
TABLE 1

Regulations for the evaluation of wine

\begin{tabular}{ll}
\hline No. & Standard for evaluation \\
\hline Appearance (10) & $0 \sim 3-$ Dull or slightly off-colour \\
Colour & $4 \sim 6-$ Bright with characteristic colour \\
Clarity & $7 \sim 10-$ Brilliant with rich colour \\
Aroma (30) & $0 \sim 5-$ Clear/marginal expression of an off-odour \\
Fruity aroma & $6 \sim 10-$ No characteristic varietal-regional-stylistic fragrance or aged bouquet \\
Fermented aroma & $11 \sim 15-$ Mild varietal-regional-stylistic fragrance or aged bouquet \\
Hierarchy & $16 \sim 20-$ Standard presence of a varietal-regional-stylistic fragrance or aged bouquet \\
& $21 \sim 25-$ Varietal-regional-stylistic fragrance or aged bouquet distance and complex \\
& $26 \sim 30-$ Varietal-regional-stylistic fragrance or aged bouquet rich, complex, refined \\
Taste (40) & $0 \sim 20-$ Acidity either too high (sharp) or too low (flat); or acid/sweetness ratio \\
Richness & inharmonious, excessively/moderate bitter and astringent; or watery or excessively \\
Clarity \& aftertaste & alcoholic; or absence/presence of typical varietal, regional, or stylistic flavour in the \\
Balance & mouth; or little/moderate lingering flavour in the mouth, pleasant aftertaste. \\
Deepness \& length & $20 \sim 40-$ Acidity appropriate for the wine style; or acid/sweetness balance \\
& invigorating, smooth mouth feel; or typical feeling of weight (substance) in mouth; \\
& or superior expression of varietal, regional, or stylistic flavour characteristics; or \\
prolonged flavour in the mouth ( $>10$ to 15 s), delicate and fined aftertaste. \\
Total quality (20) & $0 \sim 5-$ Distinctly off-character \\
Ageing potential & $6 \sim 10-$ Acceptable representation of traditional aspects of the wine type \\
Typicality & $11 \sim 15-$ Clearly better than the majority of the wines of its type \\
& $16 \sim 20-$ So nearly prefect in all sensory qualities as to be memorable
\end{tabular}

Total description

Total score (100)

\section{RESULTS}

\section{Effects of UHP treatment on the physical and chemical properties of young red wine \\ Alcohol, methanol, glycerol and $\mathrm{pH}$}

The effects of the treatments on the alcohol, methanol and glycerol contents and the $\mathrm{pH}$ value of the wine are shown in Table 2 and Table 3.

After treatment at increasing pressure levels or durations, the alcohol content was decreased, but not significantly so. The methanol content of almost all of the UHP-treatment groups was higher than that of the control, with an initial upward trend and then a downward trend as the pressure level or treatment period was increased. The glycerol content was also markedly changed by the UHP treatment, although there was no regular pattern of change. The $\mathrm{pH}$ level was not markedly changed by treatment.

\section{Total acids, volatile acids, glucose and fructose}

The effects of UHP treatment on the total acid, volatile acid, glucose and fructose contents of the wine were investigated. The total acid content (TC), also known as the titratable acidity, reflects the degree of dissociation of the total acids and their ability to form salts, which determines the acidity of the wine. UHP treatment (using different pressure levels or treatment periods) had little effect on the TC, as shown in Fig. 1. The volatile acid content of wine can reflect its hygienic condition (Li et al., 2006), and it can also be seen from Fig. 1 that the different UHP levels and treatment period had little effect on the volatile acid content.

The main monosaccharides in grape juice are glucose and fructose. Both of these are fermentable sugars, but their fermentation pathways are different. During wine fermentation, yeast will give priority to glucose (Li et al., 2006; Tronchoni et al., 2009); hence, the ratio of the glucose and fructose contents will decline. At the end of fermentation, fructose is the remaining monosaccharide in wine (Li et al., 2006). As seen in Fig. 1, after treatment under different conditions, the contents of fructose and glucose showed a certain degree of fluctuation, whereas the change in the glucose content was more obvious.

\section{Organic acids}

Variations in the four types of organic acids in the treatment groups, namely tartaric acid, citric acid, lactic acid and malic acid, are shown in Fig. 2. In general, the contents of tartaric acid, citric acid and lactic acid were significantly altered by treatment $(\mathrm{P}<0.05)$, whereas the malic acid content was not dramatically different from that of the control. Specifically, as the pressure was increased, the tartaric acid content first decreased and then increased, whereas the contents of citric acid and lactic acid showed an overall rising trend. Secondly, after treatment for different periods, the levels of the four organic acids were also significantly changed $(\mathrm{P}<0.05)$, with the tartaric acid content declining as the treatment period increased, whereas the content of lactic acid increased and that of citric acid and malic acid fluctuated and changed.

\section{Effects of UHP treatment on the chroma and hue values of the young red wine}

The changes in the chroma and hue values of the wine due to the processing conditions are shown in Fig. 3. After treatment with different levels of UHP, the chroma value of the wine was 
TABLE 2

The effects of different treatment pressures on the alcohol, methanol, and glycerol contents and the $\mathrm{pH}$ level

\begin{tabular}{lllll}
\hline Pressure $(\mathrm{MPa})$ & alcohol $(\mathrm{v} / \mathrm{v})$ & methanol $(\mathrm{g} / \mathrm{L})$ & glycerol $(\mathrm{g} / \mathrm{L})$ & $\mathrm{pH}$ \\
\hline Control & $14.63 \pm 0.01 \mathrm{a}$ & $0.23 \pm 0.01 \mathrm{c}$ & $10.22 \pm 0.02 \mathrm{c}$ & $4.37 \pm 0.00 \mathrm{a}$ \\
100 & $14.61 \pm 0.00 \mathrm{a}$ & $0.29 \pm 0.00 \mathrm{a}$ & $10.30 \pm 0.01 \mathrm{~b}$ & $4.34 \pm 0.01 \mathrm{a}$ \\
200 & $14.61 \pm 0.02 \mathrm{a}$ & $0.25 \pm 0.00 \mathrm{~b}$ & $10.17 \pm 0.03 \mathrm{c}$ & $4.36 \pm 0.00 \mathrm{a}$ \\
300 & $14.61 \pm 0.00 \mathrm{a}$ & $0.26 \pm 0.01 \mathrm{~b}$ & $10.27 \pm 0.00 \mathrm{~b}$ & $4.37 \pm 0.00 \mathrm{a}$ \\
400 & $14.60 \pm 0.01 \mathrm{a}$ & $0.27 \pm 0.00 \mathrm{ab}$ & $10.48 \pm 0.01 \mathrm{a}$ & $4.38 \pm 0.00 \mathrm{a}$ \\
500 & $14.60 \pm 0.00 \mathrm{a}$ & $0.26 \pm 0.01 \mathrm{~b}$ & $10.18 \pm 0.00 \mathrm{~d}$ & $4.37 \pm 0.01 \mathrm{a}$ \\
600 & $14.61 \pm 0.01 \mathrm{a}$ & $0.22 \pm 0.01 \mathrm{c}$ & $10.03 \pm 0.00 \mathrm{~d}$ & $4.38 \pm 0.00 \mathrm{a}$ \\
\hline
\end{tabular}

The different letters in the columns indicate significant differences (Duncan's multiple range test, $p<0.05$ ). The values are the mean values \pm SE.

TABLE 3

The effects of different treatment periods on the alcohol, methanol, and glycerol contents and the $\mathrm{pH}$ level

\begin{tabular}{lllll}
\hline Time $(\mathrm{min})$ & alcohol $(\mathrm{v} / \mathrm{v})$ & methanol $(\mathrm{g} / \mathrm{L})$ & glycerol $(\mathrm{g} / \mathrm{L})$ & $\mathrm{pH}$ \\
\hline Control & $14.63 \pm 0.00 \mathrm{a}$ & $0.23 \pm 0.00 \mathrm{c}$ & $10.22 \pm 0.01 \mathrm{~b}$ & $4.37 \pm 0.00 \mathrm{a}$ \\
5 & $14.63 \pm 0.00 \mathrm{a}$ & $0.26 \pm 0.01 \mathrm{ab}$ & $10.00 \pm 0.01 \mathrm{c}$ & $4.38 \pm 0.00 \mathrm{a}$ \\
10 & $14.61 \pm 0.01 \mathrm{a}$ & $0.26 \pm 0.00 \mathrm{ab}$ & $10.18 \pm 0.00 \mathrm{~b}$ & $4.36 \pm 0.00 \mathrm{a}$ \\
20 & $14.63 \pm 0.00 \mathrm{a}$ & $0.28 \pm 0.00 \mathrm{a}$ & $10.31 \pm 0.02 \mathrm{a}$ & $4.35 \pm 0.01 \mathrm{a}$ \\
30 & $14.60 \pm 0.00 \mathrm{a}$ & $0.25 \pm 0.00 \mathrm{~b}$ & $10.18 \pm 0.00 \mathrm{~b}$ & $4.35 \pm 0.00 \mathrm{a}$ \\
45 & $14.60 \pm 0.00 \mathrm{a}$ & $0.27 \pm 0.01 \mathrm{a}$ & $10.19 \pm 0.00 \mathrm{~b}$ & $4.36 \pm 0.00 \mathrm{a}$ \\
60 & $14.61 \pm 0.01 \mathrm{a}$ & $0.27 \pm 0.00 \mathrm{a}$ & $10.31 \pm 0.01 \mathrm{a}$ & $4.36 \pm 0.01 \mathrm{a}$ \\
\hline
\end{tabular}

The different letters in the columns indicate significant differences (Duncan's multiple range test, $\mathrm{p}<0.05$ ). The values are the mean values \pm SE.
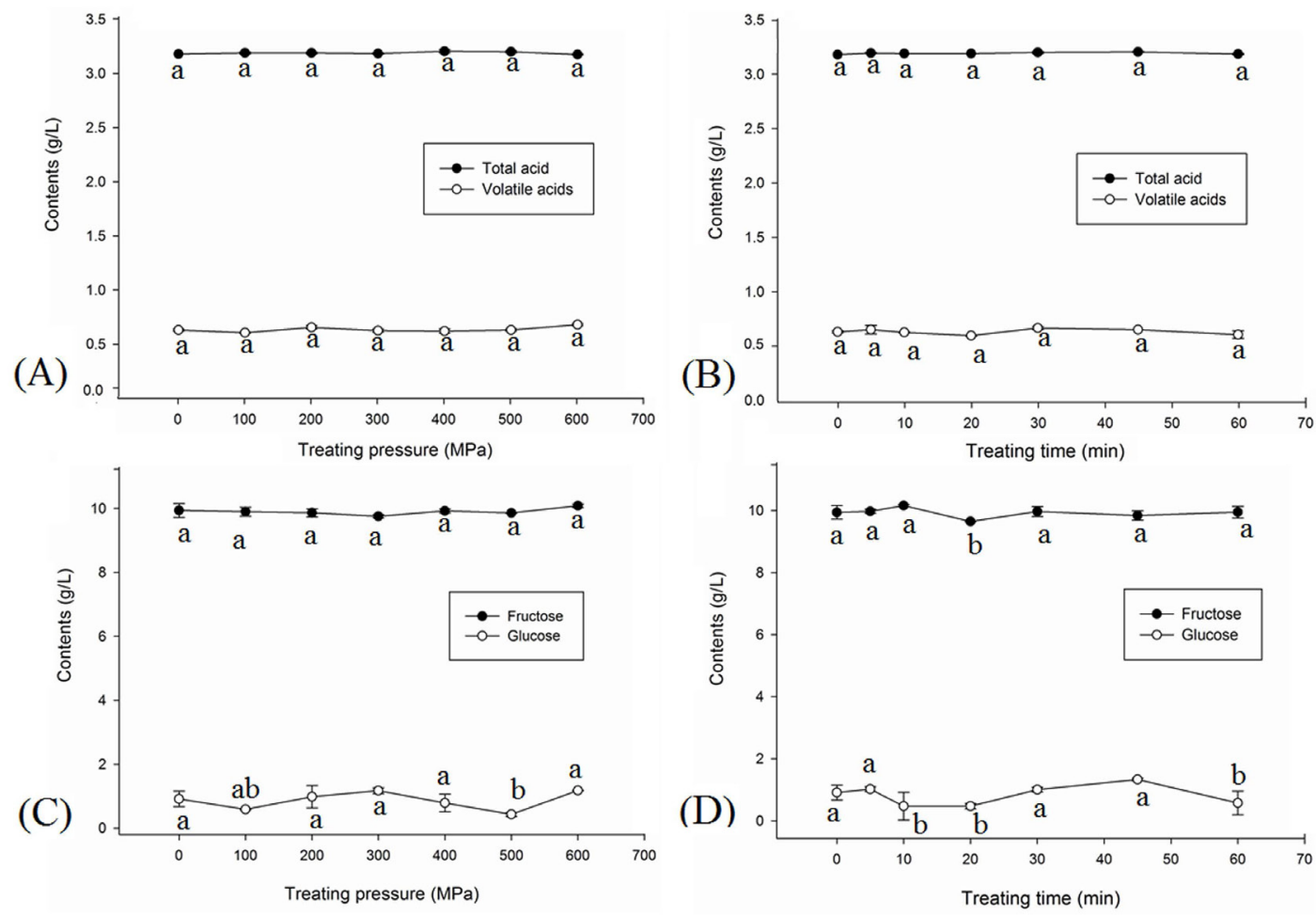

FIGURE 1

Changes in the contents of the total acids, volatile acids, fructose and glucose in the red wine treated using UHP. (A) Total acid and volatile acid contents after treatment at different pressures; (B) Total acid and volatile acid contents after treatment for different periods; (C) Fructose and glucose contents after treatment at different pressures; (D) Fructose and glucose contents after treatment for different periods; the different letters indicate significant differences (Duncan's multiple range test, $\mathrm{p}<0.05$ ). The values are the mean values $\pm \mathrm{SE}$. 
dramatically changed $(\mathrm{P}<0.05)$. As the treatment pressure was increased, the chroma value was increased, reaching the maximal level after $200 \mathrm{MPa}$ of treatment, followed by a decline as the pressure increased, until it reached the lowest level after $500 \mathrm{MPa}$ of treatment and then plateaued. The hue value of the wine fluctuated and was significantly changed $(\mathrm{P}<0.05)$ by treatments at different pressures, reaching the highest value after treatment at $400 \mathrm{MPa}$ and then decreasing as the pressure increased.

The chroma and hue values of the wine were significantly changed by UHP treatment for different periods. It is evident from Fig. 3 that the hue value was increased by $5 \mathrm{~min}$ of treatment, but when the treatment period was increased to 10 min, the hue value dropped to the lowest level, after which it followed an upward trend, reaching the highest value at 30 min of treatment, after which the value decreased as the treatment period increased.

UHP treatment increased the chroma value of the wine, which reached the maximal level after a $200 \mathrm{MPa}$ treatment and then followed a downward trend with treatment at
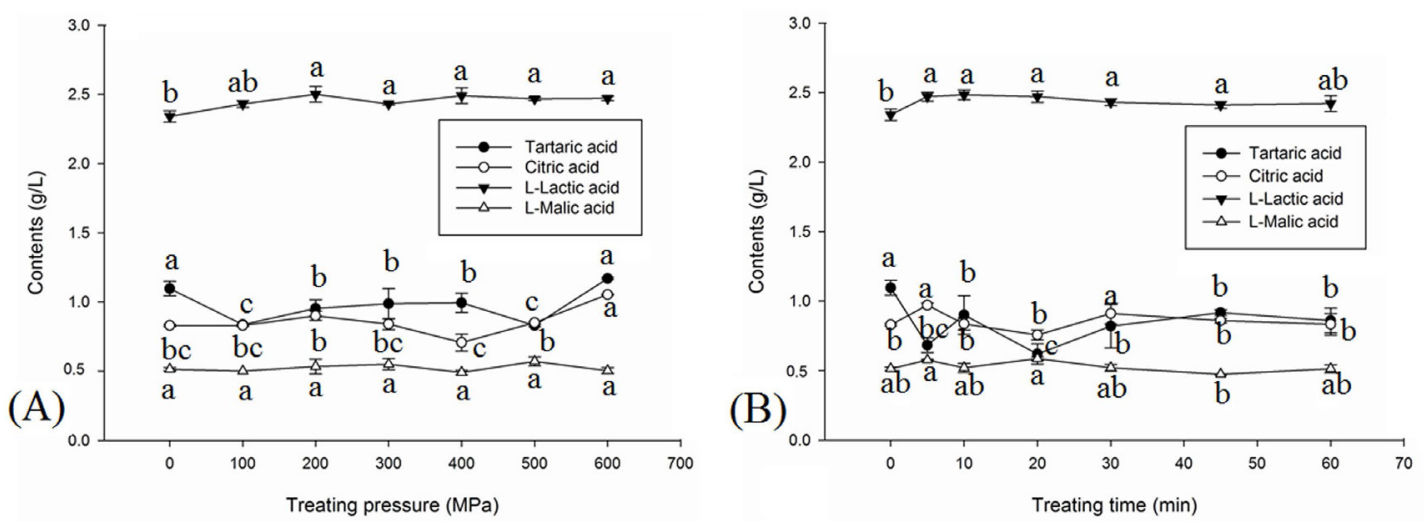

FIGURE 2

Changes in the contents of four organic acids in the red wine treated using UHP. (A) Contents after treatment at different pressures; (B) Contents after treatment for different periods; the different letters indicate significant differences (Duncan's multiple range test, $\mathrm{p}<0.05)$. The values are the mean values $\pm \mathrm{SE}$.
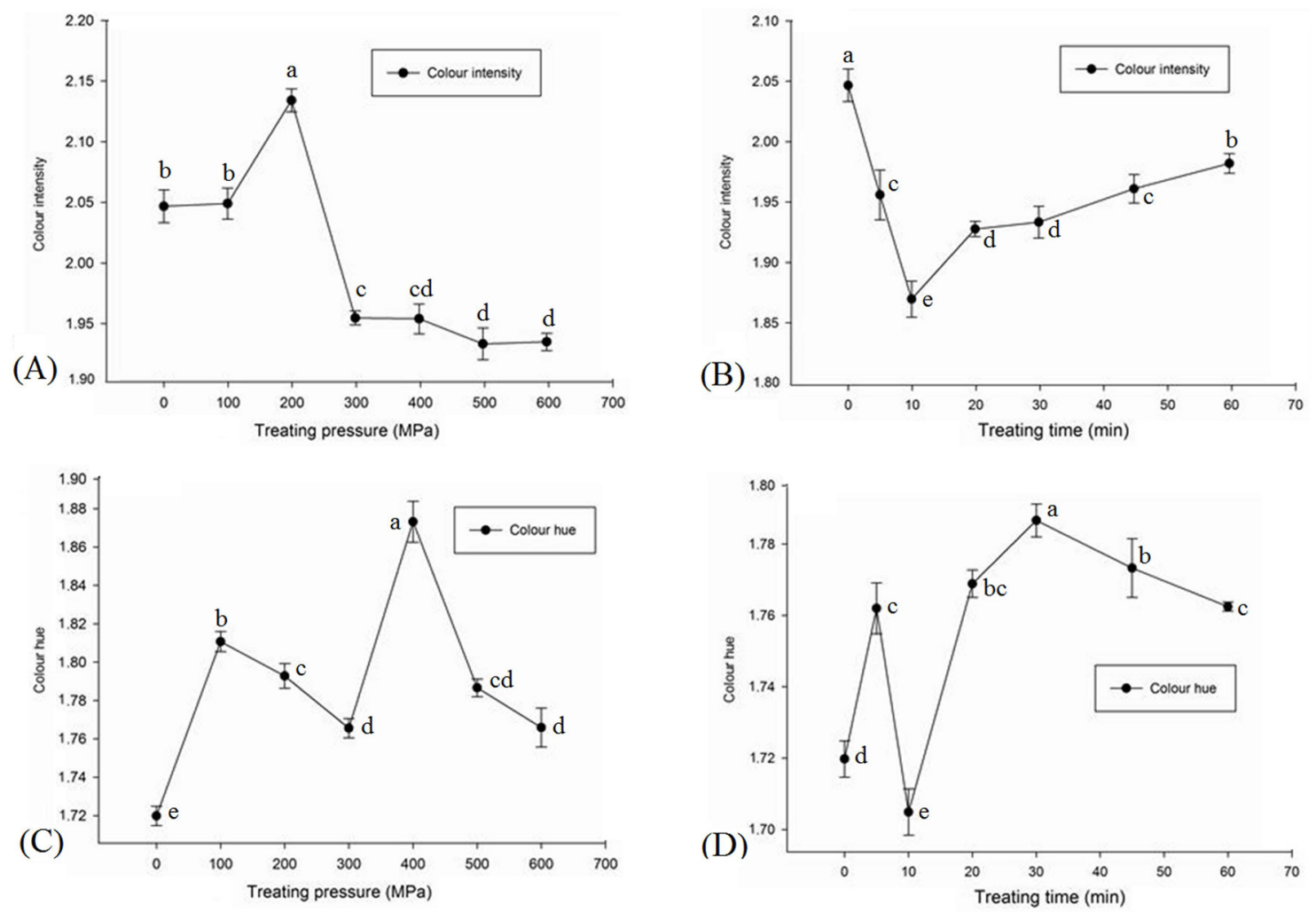

FIGURE 3

Changes in the chroma and hue values of the red wine treated using UHP. (A) Levels after treatment at different pressures; (B) Levels after treatment for different periods; the different letters indicate significant differences (Duncan's multiple range test, $\mathrm{p}<0.05)$. The values are the mean values $\pm \mathrm{SE}$. 
increased pressure levels. As the treatment period was extended, the chroma value first decreased and then showed an upward trend. The total values fluctuated but generally increased. Certain levels of high pressure can promote the participation of anthocyanin in condensation reactions, resulting in the formation of the pigment polymers that deepen the colour of wine and raises its chroma and hue values (Wang et al, 2012; Huang et al, 2013). However, a higher level of pressure may damage the structure of anthocyanin and other pigmented substances, resulting in lower colour values.

\section{Effects of UHP treatment on the sensory quality of young red wine}

The effects of the treatments on the sensory quality of the wine were evaluated by six professional tasters, and the results are shown in Fig. 4. Fig. 4A shows the effects of UHP treatment at different pressures on the appearance, aroma and taste of the wine. It can be seen from this figure that the appearance and taste of the wine were improved by these UHP treatments, but the changes are not apparent.
Whereas the aroma score was not significantly changed by treatment, the appearance score was obviously increased, with the highest score achieved when using $100 \mathrm{MPa}$. As shown in Fig. 4B, as the treatment period was prolonged, the appearance and taste values of the wine were increased significantly, whereas the aroma value was not.

Figure 5 shows the trends in the sensory evaluation scores according to the pressure and duration of treatment. After treatment at $100 \mathrm{MPa}$, the sensory score was greatly increased but, as the pressure was increased the score decreased, and then it was increased to an even higher level after treatment at $500 \mathrm{MPa}$. As the treatment period was prolonged, the sensory score showed an upward trend in volatility, and reached the highest score at $30 \mathrm{~min}$.

\section{DISCUSSION}

After water, ethanol is the second most abundant compound in wine, and it is produced mainly from sugar during alcoholic fermentation; the alcohol content is always represented by the volume percentage of ethanol (Li et al., 2006). During fermentation, the solvent properties of ethanol may promote
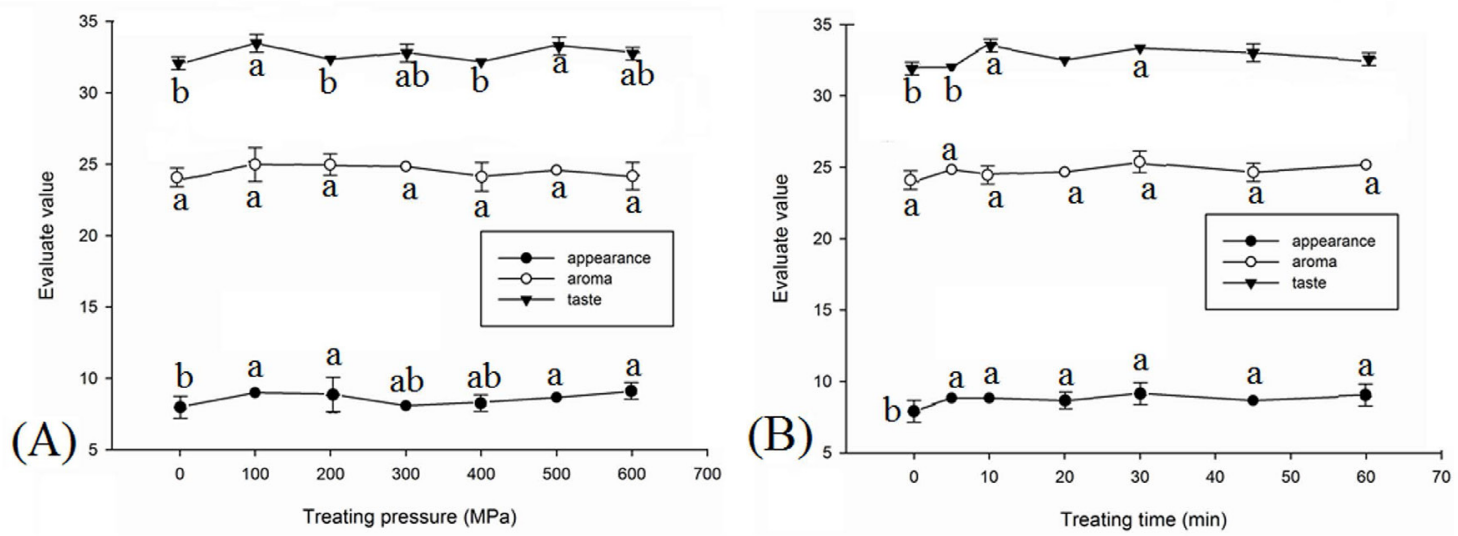

FIGURE 4

Changes in the appearance, aroma and taste of the red wine treated using UHP. (A) Values after treatment at different pressures; (B) Values after treatment for different periods; the different letters indicate significant differences (Duncan's multiple range test, $\mathrm{p}<0.05)$. The values are the mean values $\pm \mathrm{SE}$.
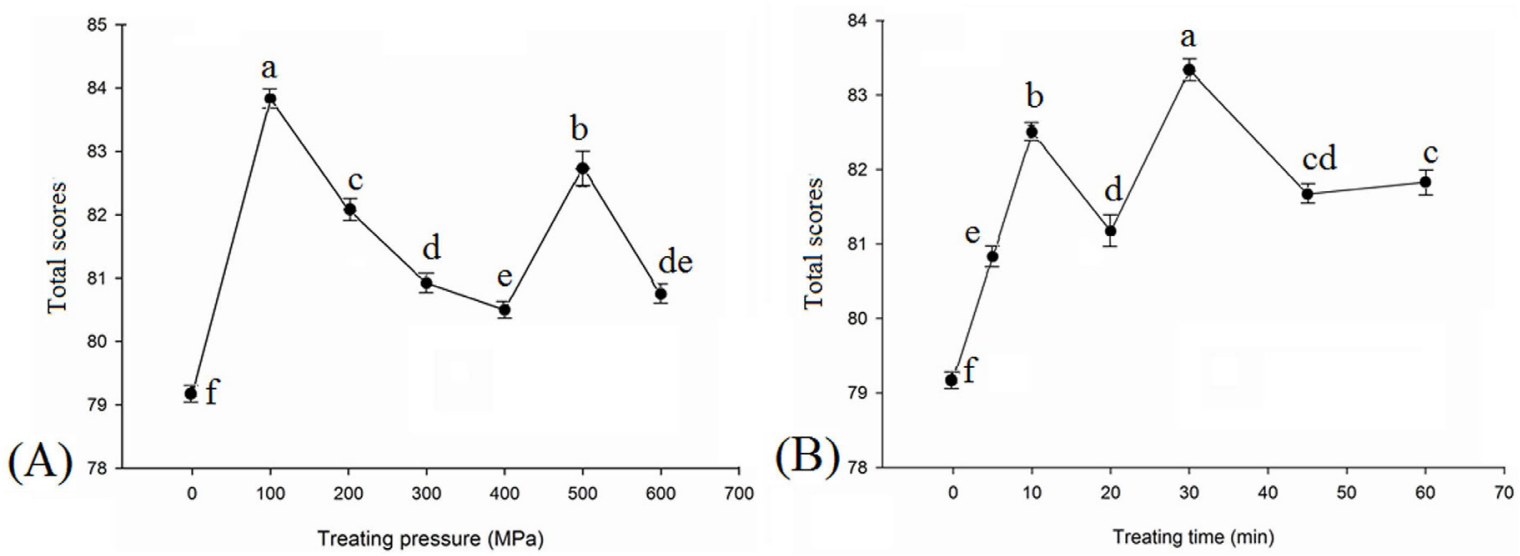

FIGURE 5

Changes in the sensory quality of the red wine treated using UHP. (A) Scores after treatment at different pressures; (B) Scores after treatment for different periods; the different letters indicate significant differences (Duncan's multiple range test, $\mathrm{p}<0.05$ ).

The values are the mean values $\pm \mathrm{SE}$. 
the dissolution of polyphenols and aromatic substances, whereas the presence of ethanol and acids maintains the stability of wine (Li et al., 2006; Villamor \& Ross, 2013). Ethanol can react with acids such as tartaric acid or malic acid to generate the corresponding ester compounds, and can react with aldehydes to generate acetal derivatives. but sulphur can prevent these reactions. After the various UHP treatments, the alcohol content of the wine was slightly lower, which may be because the UHP treatments promoted the association of ethanol and water molecules, or esterification reactions (Sencer, 2012).

Glycerol, the third most abundant compound in wine, is a by-product of alcohol fermentation and gives wine a smooth taste (Li et al., 2006). Under high-pressure conditions, intermolecular distances are shortened, which is beneficial for the association of these molecules; however, the highpressure energy can promote the esterification reaction of alcohol molecules, which may be the reason for the change in the glycerol content (Tao et al., 2012; 2013; Zhao et al., 2014). However, it is difficult to provide a reasonable explanation for the irregular pattern of change.

Organic acids are the important taste compounds in wine. Many factors can affect the types and levels of these compounds in wine, including the grape variety, the production area and the brewing and ageing processes used (Zheng et al., 2009). The organic acid content also affects the acidity of wine and plays an important role in its colour (Li et al., 2006). Tartaric acid, malic acid, lactic acid, citric acid and succinic acid are the five most important types of organic acids in wine, with lactic acid and succinic acid being produced during fermentation. The solubility of tartaric acid is affected by temperature, and some tartaric acid will precipitate during storage; moreover, during ageing, tartaric acid is esterified to generate the corresponding ester compound. During the malolactic fermentation step in the winemaking process, the malic acid content rapidly declines, while lactic acid is generated, making the taste of the wine softer. During the ageing process, malic acid and lactic acid participate in a variety of reactions, such as enzymatic reactions and oxidation-reduction reactions (Lamikanra, 1997). Studies have shown that, during ageing in bottles, the contents of tartaric acid and malic acid in wine decrease and the contents of citric acid and lactic acid increase (Wang et al., 2013). With the increased pressure levels and treatment periods, the tartaric acid content followed a downward trend, whereas the contents of citric acid and lactic acid increased with a trend similar to what occurs during natural ageing.

The degrees of chroma and hue are important indices that reflect the quality of wine. The chroma level reflects the degree of colour depth, and factors such as the concentration of anthocyanin and the aggregation of anthocyanin and auxiliary pigments affect the chroma level. The main pigment compound in young wine is anthocyanin. Free anthocyanin monomers make wine purple and, during the process of wine maturation and storage, anthocyanin and tannin polymerise to form new pigmented compounds (García-Puente et al, 2006), with the anthocyanin monomers gradually being replaced by oligomers and polymers, which gradually turns the colour of the wine brick-red. During wine ageing, the unstable anthocyanin monomers are gradually replaced by stable pigmented polymers, which increase the chroma value. The level of hue reflects the degree of maturity of the wine, and the higher the value, the more yellow is the colour of the wine, and vice versa. The hue of wine is closely related to the types and levels of polyphenols present. During the later stage of wine fermentation and in the ageing period, the 4-C and 5-OH groups of anthocyanin react with acetaldehyde, pyruvic acid, vinyl phenol, catechol vinyl, 4-ethylguaiacol, proanthocyanidin dimers or acetone, forming pyran ring structures and generating pyranoanthocyanin, which turns the colour of wine from purple to brick-red and increases the hue value (Han et al., 2008; 2009). UHP treatment changed the chroma and hue values of the wine, with the chroma value generally decreasing and the hue value generally increasing. Under UHP, the volume of the wine is compressed and the internal molecular-energy level is increased, both of which could promote the formation of pigment polymers. As a result, after treatment at $200 \mathrm{MPa}$ for $30 \mathrm{~min}$, the chroma and hue values of the wine were significantly increased. Moreover, UHP treatment can force the residual oxygen in the container into the wine, promoting the oxidisation of pigmented compounds (Iland et al., 1998), which may reduce the chroma level.

Ageing is an important part in the process of wine production; it is the maturation process of wine ( $\mathrm{Li}$ et al., 2006). In the ageing process, a series of slow and complicated changes in the physical, chemical and biological chemistry will occur in wines, which will then be endowed with a complex flavour and more soft and mellow taste, while the stability will also be improved (Li et al., 2006). Water and alcohol are the main components in wine, and in the ageing process the water molecules become associated with the alcohol molecules to make the taste more soft and mellow. At the same time a variety of complex chemical reactions take place, including the degradation of anthocyanidin, the polymerisation of anthocyanins and tannins and the oxidation of phenolic substances. UHP compresses the wine volume and changes the distance between the molecules and rearranges them, promoting associations between the molecules. The energy provided by UHP could enhance the molecular activation energy, promote the reaction of esterification, polymerisation and oxidation, and hence improve the colour, aroma and taste of wine (Sencer, 2012). This is supported by the results of the sensory quality test, which showed that the sensory scores for the wine undergoing $100 \mathrm{MPa}$ to $600 \mathrm{MPa}$ pressure treatments were all increased. The highest scores, and thus the greatest sensory quality of the wine, were recorded after treatment at $500 \mathrm{MPa}$ for 30 $\min$.

\section{CONCLUSIONS}

The UHP treatment of the wine changed the levels of some of its physical and chemical parameters, as well as its sensory quality. The alcohol content was decreased by UHP treatment, but not significantly so. The methanol content of almost all of the UHP-treatment groups was higher than that of the control, with a trend of first increasing and then decreasing with the increase in the pressure or the treatment period. The glycerol content was also markedly changed, although no regular pattern was observed. The $\mathrm{pH}$ level was not markedly 
changed by the treatments. The UHP treatments (at increased pressure levels or durations) had little effect on the total acid or volatile acid contents. The fructose and glucose contents were changed by treatment under the different conditions, with the fructose content showing a certain degree of fluctuation, whereas the change in the glucose content was more obvious. Moreover, the contents of tartaric acid, citric acid and lactic acid were significantly altered by the UHP treatment $(\mathrm{P}<0.05)$, whereas the change in the malic acid content was not dramatic. These are trends similar to those observed in natural ageing. As the pressure level of the treatment increased, the chroma value increased up to $200 \mathrm{MPa}$, when this value peaked, after which increasing the pressure decreased this value and it reached the lowest level after $500 \mathrm{MPa}$ of treatment and then plateaued. The hue value of the wine was significantly changed $(\mathrm{P}<0.05)$ by treatments at different pressures, reaching the highest value upon treatment at $400 \mathrm{MPa}$ and then decreasing with increasing pressure. The chroma and hue values of the wine were significantly changed by UHP treatment for different durations. The hue value was increased by $5 \mathrm{~min}$ of treatment, but when the treatment period was increased to $10 \mathrm{~min}$, the hue value dropped to its lowest level, and then followed an upward trend, reaching the highest value at 30 min of treatment, after which the value decreased with the increased treatment period.

A sensory evaluation is an important supplement to instrumental determinations because it is an effective method of describing the sensory quality and style of a wine and making an intuitive, comprehensive judgement of its complex composition. After UHP treatment, the appearance, aroma and taste of the wine were improved, and the appearance score obviously increased. When the wine was treated at $500 \mathrm{MPa}$ for $30 \mathrm{~min}$, its sensory quality received the highest score, demonstrating that treatment under these conditions yielded the most obvious improvement in the quality of the wine.

\section{LITERATURE CITED}

Balasubramaniam, V.M., Farkas, D. \& Turek, E., 2008. Preserving foods through high-pressure processing. Food Technol. 62, 32-38.

Chen, H. \& Hoover, D.G., 2003. Modelling the combined effect of high hydrostatic pressure and mild heat on the inactivation kinetics of Listeria monocytogenes Scott A in whole milk. Innov. Food Sci. Emerg. 4, 25-34.

Chen, X.H., Li, L., You, Y.L., Mao, B.L., Zhao, W.B. \& Zhan, J.C., 2012. The effects of ultra-high pressure treatment on the phenolic composition of red wine. S. Afr. J. Enol. Vitic. 33, 203-213.

CIE., 2004 ( $3^{\text {rd }}$ ed). Colorimetry. Technical Report 15.2. CIE, Vienna, Austria.

Corrales, M., Butz, P. \& Tauscher, B., 2008. Anthocyanin condensation reactions under high hydrostatic pressure. Food Chem. 110, 627-635.

Delfini, C. \& Conterno, L., 1995. Microbiological stabilisation of grape musts and wines by high hydrostatic pressures. J. Wine Res. 6, 143-151.

Del Pozo-Insfran, D., Del Follo-Martinez, A., Talcott, S.T. \& Brenes, C.H., 2007. Stability of copigmented anthocyanins and ascorbic acid in Muscadine grape juice processed by high hydrostatic pressure. J. Food Sci. $72,247-253$.
García-Puente, R., Alcalde-Eon, C., Santos-Buelga, C., Rivas-Gonzalo, J. \& Escribano-Bailón, M., 2006. Behaviour and characterization of the colour during red wine making and maturation. Anal. Chim. Acta 563, 215-222.

GB/T 15038, 2006. The national standard of China. Analytical methods of wine and fruit wine.

Han, B.Z. \& Tong, H.R., 2009. Food sensory evaluation. China Forestry Publishing, Beijing.

Han, F.L., Jiang, S.M., He, J.J., Pan, Q.H., Duan, C.Q. \& Zhang, M.X., 2009. Anthocyanins in "Cabernet Gernischet" (Vitis vinifera L. cv.) aged red wine and their color in aqueous solution analyzed by partial least square regression. Food Sci. Biotechnol. 18, 724-731.

Han, F.L., Zhang, W., Pan, Q.H., Zheng, C., Chen, H. \& Duan, C.Q., 2008. Principal component regression analysis of the relation between CIELAB color and monomeric anthocyanins in young Cabernet Sauvignon wines. Molecules 13, 2859-2870.

Huang, W.S., Bi, X., Zhang, X., Liao, X.J., Hu, X.S. \& Wu, J.H., 2013. Comparative study of enzymes, phenolics, carotenoids and color of apricot nectars treated by high hydrostatic pressure and high temperature short time. Innov. Food Sci, Emerg. 18, 74-82.

Iland, P.G., Peng, Z.K., Pfenning, G., Ford, C.F. \& Hoj, P.B., 1998. Changes in the phenolic compositions of Shiraz grapes during ripening. In: Proceedings of the Tenth Australian Wine Industry Technical Conference, p. 260.

Lamikanra, O., 1997. Changes in organic acid composition during fermentation and aging of Noble Muscatine wine. J. Agric. Food Chem. $45,935-937$.

Li, H., Wang, H., Yuan, C.L. \& Wang, S.S., 2006. Wine chemistry. Science Press, Beijing.

Ma, T.T., Sun, X.Y., Gao, G.T., Wang, X.Y., Liu, X.Y., Du, G.R. \& Zhan, J.C., 2014. Phenolic characterisation and antioxidant capacity of young wines made from different grape varieties grown in Helanshan Donglu Wine Zone (China). S. Afr. J. Enol. Vitic. 35, 321-331.

Matser, A.M., Krebbers, B., Van den Berg, R.W. \& Bartels, P.V., 2004. Advantages of high pressure sterilisation on quality of food products. Trends Food Sci. Technol. 15, 79-85.

Mok, C., Song, K., Park, Y., Lim, S., Ruan, R. \& Chen, P., 2006. High hydrostatic pressure pasteurization of red wine. J. Food Sci. 71, 265-269.

Morata, A., Benito, S., González, M., Palomero, F., Tesfaye, W. \& SuárezLepe, J., 2012. Cold pasteurisation of red wines with high hydrostatic pressure to control Dekkera/ Brettanomyces: Effect on both aromatic and chromatic quality of wine. Eur. Food Res. Technol. 235, 147-154.

Morata, A., Loira, I., Vejerano, R., Bañuelos, M.A., Sanz, P.D., Otero, L. \& Suárez-Lepe, J.A., 2015. Grape processing by high hydrostatic pressure: Effect on microbial populations, phenol extraction and wine quality. Food Bioprocess. Technol, 8, 277-286.

Park, H., Kim, K. \& Jeong, H., 2009. Quality changes of jujube wine by hydrostatic pressure and freezing treatment during storage. J. Korean Soc. Food Sci. Nutr. 38(1), 89-97.

Park, H., Kim, K., Han, G. \& Jeong, H., 2007. Quality of jujube wine with hydrostatic pressure and freezing treatment. J. Korean Soc. Food. Sci. Nutr. 36(11), 1444-1450.

Pehl, M., Werner, F. \& Delgado, A., 2000. First visualization of temperature fields in liquids at high pressure using thermochromic liquid crystals. Exp. Fluids 29, 302-304

PN-ISO 8589:1998, Sensory analysis - General guidance for laboratory of sensory analysis. 
Santos, M., Nunes, C., Cappelle, J., Gonalves, F., Rodrigues, A., Saraiva, J. \& Coimbra, M., 2013a. Effect of high pressure treatments on the physicochemical properties of a sulphur dioxide-free red wine. Food Chem. $141,2558-2566$

Santos, M.C., Nunes, C., Rocha, M.A.M., Rodrigues, A., Rocha, S.M., Saraiva, J.A. \& Coimbra, M.A., 2013b. Impact of high pressure treatments on the physicochemical properties of a sulphur dioxide-free white wine during bottle storage: evidence for Maillard reaction acceleration. Innov. Food Sci. Emerg. 20, 51-58.

Sencer, B., 2012. High hydrostatic pressure treatment of beer and wine: A review. Innov. Food Sci. Emerg. 13, 1-12.

Soriano, A., Perez-Juan, P.M., Vicario, A., Gonzalez, J.M. \& Perez-Coello, M.S., 2007. Determination of anthocyanins in red wine using a newly developed method based on Fourier transform infrared spectroscopy. Food Chem. 104, 1295-1303.

Sun, X.Y., Du, G.R., Ma, T.T., Liu, X.Y., Wang, X.Y. \& Zhan, J.C., 2014. Polyphenol composition and antioxidant activity of domestic wines from Shaanxi province. Modern Food Sci. Technol. 30, 242-250.

Tabilo-Munizaga, G., Gordon, T.A., Villalobos-Carvajal, R., MorenoOsorio, L., Salazar, F.N., Pérez-Won, M. \& Acuña, S., 2014. Effects of high hydrostatic pressure (HHP) on the protein structure and thermal stability of Sauvignon blanc wine. Food Chem. 155, 214-220.

Tao, Y., Sun, D.W., Górecki, A., Blaszczak, W., Lamparski, G., Amarowicz, R., Fornal, J. \& Jeliński, T., 2012. Effects of high hydrostatic pressure processing on the physicochemical and sensorial properties of a red wine. Innov. Food Sci. Emerg. 16, 409-416

Tao, Y., Wu, D., Sun, D.W., Górecki, A., Blaszczak, W., Fornal, J. \& Jeliński, T., 2013. Quantitative and predictive study of the evolution of wine quality parameters during high hydrostatic pressure processing. Innov. Food Sci. Emerg. 20, 81-90.
The National Standard of China, GB/T 15038-2006. Analytical methods of wine and fruit wine.

Tronchoni, J., Gamero, A., Arroyo-López, F.N., Barrio, E. \& Querol, A., 2009. Differences in the glucose and fructose consumption profiles in diverse Saccharomyces wine species and their hybrids during grape juice fermentation. Innov. Food Sci. Emerg. 134, 237-243.

Villamor, R.R. \& Ross, C.F., 2013. Wine Matrix Compounds Affect Perception of Wine Aromas. Annu Rev Food Sci Technol. 4, 1-20.

Wang, R.R., Wang, T.T, Zheng, Q., Hu, X.S., Zhang, Y. \& Liao, X.J., 2012. Effects of high hydrostatic pressure on color of spinach purée and related properties. J. Sci. Food Agric. 92, 1417-1423.

Wang, X.Q., Su, H.N., Zhang, Q.H. \& Yang, P.P., 2013. The effects of pulsed electric fields applied to red and white wines during bottle aging on organic acid contents. J. Food Sci. Technol. 52, 171-180.

Winiarski, W., Winiarski, J. \& Silacci, M. \& Painter, B., 1996. The Davis 20 -point scale: How does it score today? - wine scoring system. Wines \& Vines 77, 50-53.

Wyszecki, G. \& Stiles, W.S., 1982 ( $2^{\text {nd }}$ ed). Color science: Concepts and methods, quantitative data and formulae. John Wiley and Sons, New York.

Zhao, L., Wang, Y.T., Qiu, D.D. \& Liao, X.J., 2014. Effect of ultrafiltration combined with high-pressure processing on safety and quality features of fresh apple juice. Food Bioprocess. Tech. 7, 3246-3258.

Zheng, Y.J., Duan, Y.T., Zhang, Y.F., Pan, Q.H., Li, J.M. \& Huang, W.D., 2009. Determination of organic acids in red wine and must on only one RPLC-Column directly after sample dilution and filtration. Chromatographia 69, 1391-1395 